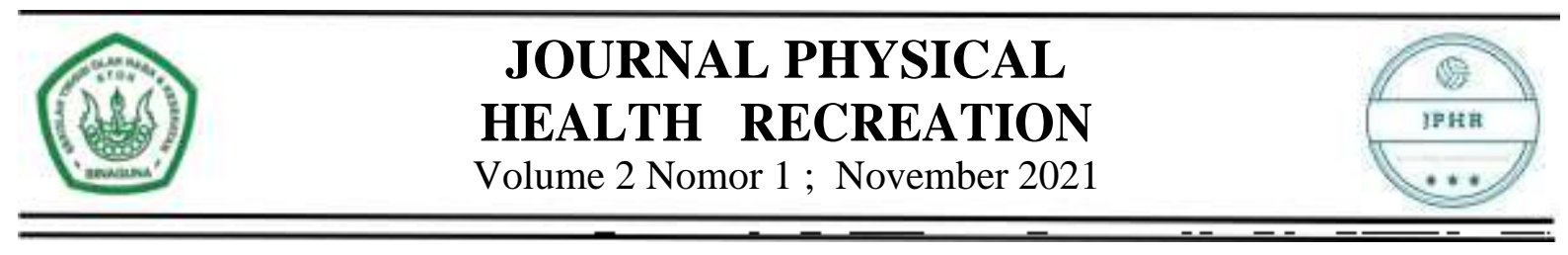

\title{
PENGARUH LATIHAN CIRCUIT TRAINING UNTUK MENINGKATKAN KESEGARAN JASMANI ATLIT PENCAK SILAT USIA DINI (9-12 TAHUN) DI PERGURUAN TAPAK SUCI GELANGGANG SD MUHAMMADIYAH 18 MEDAN
}

\author{
Dede Pebriandi Sihotang ${ }^{1}$, Novita ${ }^{2}$ \\ ${ }^{1}$ Universitas Negeri Medan \\ Jl. William Iskandar Ps. V, Kenangan Baru, Sumatera Utara \\ Email : dede.pebriandi123@gmail.com
}

\begin{abstract}
The purpose of this study was to determine whether or not circuit training had an effect on improving the physical fitness of early age pencak silat athletes (9-12 years) at tapak suci arena college, sd muhammadiyah 18 medan. This research was conducted at the muhammadiyah 18 elementary school medan. This research was started from 14 november to 26 december. This research is an experimental research with one group pretest-posttest design research method. The subjects of this study were early age of martial arts athletes (9-12 years) at the tapak suci arena college, sd muhammadiyah 18 medan, totaling 20 athletes. The instrument used was the tkji (indonesian physical fitness test), including the straight jumping test, bending elbow test, sittingdown test, 40-meter running test, 600-meter running test. The data analysis technique used t-test at a significant level of $\alpha=0.05$. The results of the research on the effect of circuit training on improving the physical fitness of early age pencak silat athletes (9-12 years) at Tapak Suci Gelanggang college, SD Muhammadiyah 18 Medan. From the analysis of the results of the data that has been carried out by statistical tests, it is obtained t-count of 111.8. Furthermore, this value is compared with the t-table value with $d k=n-1(20-1=19)$ at the significant level $\alpha=0.05$ is 2.09, thus t-count> t-table $(111.8>2.09)$ can be concluded that through Application of Circuit Training training can improve physical fitness in early childhood pencak silat (9-12 years) at Tapak Suci College arena, SD Muhammadiyah 18 Medan in 2020. These results are interpreted as accepted, so the hypothesis states there is an effect of circuit training training on improving athlete's physical fitness. Early childhood martial arts (9-12 years) at the Tapak Suci college arena, Muhammadiyah 18 Elementary School, Medan..
\end{abstract}

Keywords: circuit training,physical fitness, martial arts

\section{ABSTRAK}


Tujuan penelitian ini adalah untuk ada atau tidaknya pengaruh latihan circuit training terhadap peningkatan kesegaran jasmani atlet pencak silat usia dini (9-12 tahun) di perguruan Tapak Suci Gelanggang SD Muhammadiyah 18 Medan.Penelitian ini dilakukan di gelanggang SD Muhammadiyah 18 Medan.Penelitian ini dimulai dari bulan Oktober-Desember.Penelitian ini merupakan penelitian eksperimen dengan metode penelitian one group pretest-posttest design. Subjek penelitian ini adalah atlet pencak silat usia dini (9-12 tahun) di perguruan Tapak Suci Gelanggang SD Muhammadiyah 18 Medan yang berjumlah 20 atlet. Instrument yang digunakan adalah TKJI (Tes Kebugaran Jasmani Indonesia) antara lain tes loncat tegak, tes siku tekuk, tes baring duduk, tes lari 40 meter, tes lari 600 meter. Teknik analisis data menggunakan uji-t pada taraf signifikan $\alpha=0,05$. Hasil penelitian pengaruh latihan circuit training terhadap peningkatan kesegaran jasmani atlet pencak silat usia dini (9-12 tahun) di perguruan Tapak Suci Gelanggang SD Muhammadiyah 18 Medan. Dari analisishasil data yang telahdilakukan dengan uji statistik diperoleh t_hitung sebesar 111,8. Selanjutnya nilai tersebut dibandingkan dengan nilai t_tabel dengan $\mathrm{dk}=\mathrm{n}-1 \quad(20-1=19)$ pada taraf signifikan $\alpha=0,05$ adalah 2,09 dengan demikian t_hitung>t_tabel $(111,8>2,09)$ dapat disimpulkan bahwa melalui penerapan latihan Circuit Training dapat meningkatkan kesegaran jasmani pada pencak silat usia dini (9-12 tahun) di Perguruan Tapak Suci Gelanggang SD Muhammadiyah 18 Medan Tahun 2020. Hasil tersebut diartikan hipotesisditerima, sehingga hipotesisnya menyatakan ada pengaruh latihan circuit training terhadap peningkatan kesegaran jasmani atlet pencak silat usia dini (9-12 tahun) di perguruan Tapak Suci Gelanggang SD Muhammadiyah 18 Medan .

\section{Kata kunci: latihan Circuit Training, Anak Usia Dini.Dan Kesegaran Jasmani.}

\section{PENDAHULUAN}

Pencak silat khususnya nomor tanding, menuntut para atlit/pesilat untuk mengubah arah secara cepat, memukul dan menendang dengan cepat, serta menuntut daya tahan. Disamping itu dibutuhkan juga kecerdikan, ketelitian, kecepatan bertindak, dan kordinasi gerak.

Masuknya Tapak Suci ke Medan diprakarsai oleh Nazir Musa dan Bambang S pada tahun 1970, 7 (tujuh) tahun setelah dibentuknya Perguruan Tapak Suci di Kauman, Yogyakarta. Di beberapa sekolah di Kota Medan Pencak Silat di bawah Perguruan Tapak Suci sudah menjadi bagian ekstrakurikuler, salah satunya di sekolah SD Muhammadiyah 18 Medan dengan nama perguruan Tapak Suci Gelanggang SD yang mulai didirikan pada tahun 2016. Perguruan Tapak Suci SD muhammadiyah 18 ini melakukan pembinan di usia dini yakni usia 9 (sembilan) sampai 12 (dua belas) tahun. Perguruan ini telah banyak mengikuti beberapa pertandingan yang diselenggarakan oleh IPSI Kota Medan dan Antar Gelanggang Se-Kota Medan. Walaupun terbilang masih muda namun perguruan ini telah mencapai beberapa prestasi gemilang pada tahun 2019 antara lain : (1) Juara Umum 1 Pelita Cup, (2) Gang Jawa Cup, (3) Juara 1 O2SN Kota Medan 2019, (4) Juara Umum 1 Porseni SMP 
Muhammadiyah 01 Medan dan sebagainya.. Pencapaian prestasi atlet perguruan Tapak Suci SD Muhammadiyah 18 Medan tentunya tidak terlepas dari berbagai faktor, salah satunya adalah faktor kondisi fisik. Fisik merupakan pondasi dari prestasi olahraga sebab teknik, taktik dan mental akan dapat dikembangkan dengan baik jika memiliki kualitas fisik yang baik (Hinda Zhannisa \& Sugiyanto, 2015).

Pelatih dalam menghasilkan prestasi atlet yang tangguh perlu dipersiapkan sesuai tahap-tahap calon atlet. Peletakkan dasar bangunan prestasi yang dilaksanakan pada tahap dasar yakni perkembangan multilateral. Pada tahap multilateral dari umur 6 sampai 14. Perkembangan multilateral adalah penting bagi anak-anak muda untuk mengembangkan berbagai keterampilan pokok untuk membentuknya menjadi atlet segala cabang sebelum mereka memulai pelatihan dalam suatu olahraga spesifik. Anak-anak mengembangkan keterampilan dasar seperti jalan, lompat, lempar, tangkap, guling, dan keseimbangan (Bompa, 2000: 3). Selain itu, tujuan perkembangan multilateral adalah meningkatkan seluruh adaptasi, masa anak-anak dan muda mengembangkan berbagai kemampuan motorik dan keterampilan teknik tanpa adanya beban latihan, dan pelatihan harus bersifat permainan yang menyenangkan. Dari hasil tinjauan di lapangan dilihat bahwasanya prestasi atlit tidak sesuai dengan kesegaran jasmani atlet. Ini bisa jadi dikarenakan oleh program latihan yang kurang tepat ataupun pemahaman pelatih yang kurang mampu dalam menyusun program untuk usia dini. Yang seharusnya atlit usia dini adalah diberikan konsep pelatihan biomotor dasar.
e-ISSN : 2747- 013X

Dengan mengetahui status kesegaran jasmani awal, maka akan lebih lengkap dijadikan sebagai bahan untuk pengembangan kesegaran jasmani atlet udia dini SD Muhammadiyah 18 Medan. "Latihan ialah upaya sadar yang dilakukan secara berkelanjutan dan sistematis untuk meningkatkan kemampuan fungsional raga yang sesuai dengan tuntutan tugas atau penampilan cabang olahraga yang bersangkutan, untuk dapat menampilkan mutu tinggi cabang olahraga itu baik pada aspek kemampuan dasar (kemampuan fisik) maupun pada aspek kemampuan keterampilannya (kemampuan teknik) (Giriwijoyo \& Dikdik, 2012: 316).

Perguruan Tapak Suci SD Muhammadiyah 18 Medan merupakan salah satu wadah dalam naungan Organisasi Muhammadiyah dan Kependidikan yang memuat sebuah kegiatan terprogram dan terarah. Tahun 2019 perguruan tersebut berhasil meraih prestasi yang bagus, yaitu (1) Juara Umum 1 Pelita Cup (2) Gang Jawa Cup (3) Juara 1 O2SN Kota Medan 2019 (4) Juara Umum 1 Porseni SMP Muhammadiyah 01 Medan.

Dibalik prestasi yang bagus itu, ada kendala yang dihadapi pelatih yaitu kesegaran jasmani yang rendah. Dilihat dari hasil tes pelatih dan tes pendahuluan penulis. Dari hasil terlihat bahwasanya prestasi tidak seimbang dengan kemampuan kesegaran fisik atlit. Yang dikhawatirkan adalah terjadinya ketidaktepatan program latihan fisik dengan usia atlet. Dari situ peneliti ingin memberikan latihan circuit training yang sesuai dengan progres saat ini. Karena pemberian program latihan yang benar dan tepat akan memberikan kontribusi yang signifikan terhadap pencapaian prestasi 
jangka panjang tanpa mengabaikan usia pertumbuhan dan perkembangan anak.

\section{METODE PENELITIAN}

Tempat dan Waktu Penelitian

Lokasi Penelitian

Penelitian ini dilaksanakan di SD Muhammadiyah18 Medan, Jl. Pelita No. 5 Sidorame Barat 1, Kec. Medan Perjuangan, Kota Medan, Sumatera Utara

Waktu Penelitian

Penelitian ini dilaksanakan pada 14November - 26 Desember 2020, selama 6 minggu, frekuensilatihan 3 kali dalam seminggu. Jumlah latihan sebanyak 18 kali pertemuan. Dimulai pada saat pelaksanaan pengambilan data pre- test yangdilaksanakan pada 14 November 2020 dan post - test pada26 Desember 2020.

\section{Populasi dan Sampel}

Populasi Penelitian

Populasi adalah wilayah generalisasi yang tediri atas objek yang mempunyai kualitas dan karakteristik tertentu yang ditetapkan oleh peneliti untuk dipelajari dan kemudian ditarik kesimpulannya (Sugiyono, 2005: 117). Populasi pada penelitian ini adalah atlet pelajar usia 9-12 tahun Perguruan Tapak Suci SD Muhammadiyah 18 Medan yang berjumlah 60 orang.

Sampel penelitian
e-ISSN : 2747- 013X

Sampel adalah sebagian dari jumlah karakteristik yang dimiliki boleh populasi tersebut (Sugiyono, 1997: 56). Sampel yang diambil dari populasi harus representatif (mewakili). Sampel dalam penelitian ini ditentukan secara purposive sampling, yaitu mengambil sampel berdasarkan pertimbangan. Pertimbangan

peneliti dalam mengambil sampel ini yaitu pesilat usia dini putra dan pernah berprestasi ditingkat Kota dan Kecamatan dengan jumlah 20 atlet.

\section{Metode Penelitian}

Menurut Sugiyono (2008: 107) bahwa penelitian eksperimen adalah penelitian yang digunakan untuk mencari pengaruh perlakuan tertentu terhadap yang lain dalam kondisi yang terkendalikan. Metode Penelitian yang digunakan dalam penelitian ini adalah metode Eksperimen dengan tenik pengambilan data yang melibatkan satu variable bebas yaitu latihan circuit training untuk atlet usia dini dan satu variable terikat yaitu kesegaran jasmani atlet usia dini.

Desain Penelitian

Penelitian ini termasuk dalam penelitian deskriptif yang salah satu cirinya adalah tidak adanya hipotesis dan data yang terkumpul dipersentasikan dan dicari standar 
deviasinya. Dengan teknik pengumpulan data dan menggunakan teknik tes dan pengukuran. Data yang diperoleh dari tes dan pengukuran yang dilakukan oleh pengukur terhadap sampel. Sampel penelitian adalah atlet pencak silat Usia dini 9-12 tahunputra dalam kategori tanding yang ditentukan secara purposive samplingdan atlet yang berkenan hadir dalam pengambilan data.

Adapun langkah langkah penelitian yang akan dilaksanakan adalah sebagai berikut;

a) menetapkan populasi,

b) menetapkan sampel,

c) melakukan tesawal,

d) melakukan Treatment,

e) melakukan tesakhir,

f) pengelolahan data dan analisis data,

g) menarik kesimpulan.

Instrument penelitian adalah alat-alat yang digunakan dalam peelitian terutama yang berkaitan dengan proses pegambilan data. Seperti dikemukakan Sugiyono (2010: 148), "instrument penelitian adalah suatu alat yang digunakan untuk mengukur fenomena alam maupun sosial yang diamati”. Alat ini diperlukan agar mendapatkan data yang selanjutnya dapat diolah dan dianalisa. Dalam penelitian ini penulis menggunakan metode observasi dengan bentuk instrumen berupa lembar observasi tes dan pengukuran kesegaran jasmani. Dalam penelitian ini pelaksanaan treatmen dilaksanakan selama 18 kali pertemuan, yang dilakukan setiap minggu 3 kali pertemuan. Jumlah pertemuan dibagi 3 kali setiap mingguuntuk kelompok sampel sehingga ada 6 minggu. Hal tersebut sessuai yang dipaparkan oleh Sarwono dan Ismaryati (1999: 43) “ frekuensi jumlah waktu ulangan latihan yang baik adalah dilakukan 5-6 pers sesi latihan atau 2-4 kali per minggu.

Instrument Tes yang digunakan yaitu Tes Kesegaran Jasmani Indonesia (TKJI). Dalam lokakarya kesegaran jasmani yang dilaksanakan pada tahun 1984 “ Tes Kesegaran Jasmani Indonesia " (TKJI) telah disepakati dan ditetapkan menjadi instrumen/alat tes yang berlaku di seluruh wilayah Indonesia karena TKJI disusun dan disesuaikan dengan kondisi anak Indonesia. TKJI dibagi dalam 4 kelompok usia, yaitu : 6-9 tahun, 10-12 tahun, 13-15 tahun, dan 1619 tahun.

1. Lari 40 meter

2. Tes Gantung Siku Tekuk

3. Tes Baring Duduk 30 detik

4. Tes Loncat Tegak

5. Tes Lari 600 meter

\section{HASIL DAN PEMBAHASAN}

Deskripsi Data Penelitian 
Hasil tes dan pengukuran yang dilakukan dilapangan merupakan temuan penelitian yang dilakukan selama 18 kali pertemuan. Dilakukan untuk mengungkapkan kebenaran hipotase yang telah diajukan. Hasil tes dan pengukuran yang telah diolah melalui rumus statistis menunjukkan deskripsi data sebagai berikut:

\begin{tabular}{|c|c|c|}
\hline \multirow{2}{*}{ Deskripsi Data } & \multicolumn{2}{|c|}{ Data Hasil Kesegaran jasmani } \\
\cline { 2 - 3 } & Pre-test & Post-test \\
\hline Nilai Minimum & 14 & 19 \\
\hline Nilai Maksimum & 18 & 23 \\
\hline Nilai Rata-Rata & 16,0 & 20,25 \\
\hline Simpangan Baku & 1,45 & 1,06 \\
\hline
\end{tabular}

Dari data-data di atas dapat diketahui data pre-test dengan rentang nilai dari 14 (minimum) sampai 18 (maksimum), sedangkan nilai rata-rata 16,0 dan simpangan baku adalah 1,45. Untuk data post-test diperoleh rentang nilai dari 19 (minimum) sampai 23 (maksimum), sedangkan nilai ratarata adalah 20,25 dan simpangan baku adalah 1,06 .

Untuk lebih jelasnya mengenai peningkatan kesegaran jasmani atlet pencak silat usia dini(9-12 tahun) di perguruan tapak suci gelanggang SD Muhammadiyah 18 Medan setelah diberi perlakuan latihan circuit training dapat dilihat pada histogram berikut ini :
Pengujian Persyaratan Analisis Pengujian persyaratan analisis merupakan persyaratan yang harus dipenuhi sebelum dilakukan analisis uji-t. Ada dua syarat harus dipenuhi sebelum melakukan analisis uji-t, yaitu (1) uji normalitas dan (2) uji homogenitas varians populasi. Untuk uji normalitas data dalam penelitian ini menggunakan uji Lillifors dan untuk uji homogenitas varians populasi menggunakan Uji Varians keduanya pada taraf signifikansi $\square=0,05 \%$

\section{Uji Normalitas Data}

Berdasarkan perhitungan uji normalitas data yang terdapat pada lampiran 3 dan lampiran 4 diperoleh hasil uji normalitas data pre- test dan post-test. Data pre-test diperoleh nilai Lo = 0,154652 sedangkan nilai Ltabel $=0,190(\mathrm{n}=$ 20 dan taraf signifikan $\alpha=0,05 \%$ ). Sehingga dapat disimpulkan bahwa data pre-tes tingkat kesegaran jasmani atlet pencak silat usia dini (9-12 tahun) di perguruan tapak suci gelanggang SD Muhammadiyah 18 Medan berasal dari populasi yang berdistribusi normal. Untuk data post-test diperoleh nilai Lo $=0,242376$ sedangkan nilai Ltabel $=$ $0,190(\mathrm{n}=20$ dan taraf signifikan $\alpha=0,05$ $\%)$. Sehingga dapat disimpulkan bahwa data post-test tingkat kesegaran jasmaniatlet pencak silat usia dini (9-12 tahun) perguruan 
tapak suci gelanggang SD Muhammadiyah

18 Medan berasal dari populasi yang berdistribusi normal.

Untuk lebih jelasnya mengenai hasil perhitungan uji normalitas data dapat dilihat pada tabel berikut ini.

\begin{tabular}{|c|c|c|c|}
\hline $\begin{array}{c}\text { Kelompok } \\
\text { data }\end{array}$ & Nilai $\mathbf{L}_{\mathbf{0}}$ & Nilai $\mathbf{L}_{\text {tabel }}$ & Kesimpulan \\
\hline Pre-test & 0,154652 & 0,190 & Normal \\
\hline Post-test & 0,242376 & 0,190 & Normal \\
\hline
\end{tabular}

Uji Homogenitas

Hasil perhitungan Uji Homogenitas adalah sebagai berikut :

Varians data hasilPre-test $=1,, 45$

Variansdata hasilPost-test $=1,06$

Uji homogenitas dari data pre-test dan post-test hasil Kesegaran jasmani diperoleh F_hitung $=1,11$, diketahui $\mathrm{n}=20 \mathrm{v}=\mathrm{N}-1=$ 20-1= 19 sehingga didapat $F_{-}((0,05)(19,19))$ $=2,16$ dengan taraf nyata $\alpha=0,05 \%$ maka F_hitung $<$ F_tabel $\quad(1,06<2,16) \quad$ dapat disimpulkan bahwa data berasal dari varians yang homogen.

Pengujian Hipotesis

Pengujian Hipotesis dilakukan dengan uji-t untuk mengetahui pengaruh dari latihan Circuit Training terhadap peningkatan kesegaran jasmani. Berdasarkan hasil perhitungan yang dilakukan maka diperoleh t_hitung sebesar 111,8. Selanjutnya nilai tersebut dibandingkan dengan nilai t_tabel dengan $\mathrm{dk}=\mathrm{n}-1$ (201=19) pada taraf signifikan $\alpha=0,05 \%$ adalah
2,09 dengandemikian t_hitung > t_tabel (111,8> 2,09). Hal ini berarti H_0 ditolak H_a diterima. Dengan demikian dapat disimpulkan bahwa latihan Circuit Training memberikan pengaruh yang signifikan terhadap peningkatan kesegaran jasmani atlet pencak silat usia dini (9-12 tahun) di Perguruan Tapak Suci Gelanggang SD Muhammadiyah 18 Medan Tahun 2020.

Pembahasan Penelitian

Dari analisis hasil data yang telah dilakukan dengan uji statistik dapat disimpulkan bahwa melalui penerapan latihan Circuit Training dapat meningkatkan kesegaran jasmani pada pencak silat usia dini (9-12 tahun) di Perguruan Tapak Suci Gelanggang SD Muhammadiyah 18 Medan Tahun 2020. Dari hasil analisis data juga dapat diketahui bahwa hasil pre-test masih rendah, maka dilakukan penerapan latihan Circuit Training pada proses latihan atlet.

Dalam penelitian ini,latihan Circuit Training mempunyai maksud untuk melihat pengaruhnya terhadap peningkatan kesegaran jasmani pada atlet pencak silat usia dini (9-12 tahun) di Perguruan Tapak Suci Gelanggang SD Muhammadiyah 18 Medan Tahun 2020. Dengan diberikannya latihan selama 6 minggu dapat memberikan pengetahuan baru dalam hal melatih fisik dan 
juga memberikan pengalaman tersendiri bagi atlet. Kesegaran jasmani sangat penting bagi kehidupan manusia, apalagi sebagai seorang atlet olahraga, khususnya pencak silat. Kesegaran jasmani merupakan faktor yang penting bagi seorang atlit pencak silat khususnya kategori tanding. Kesegaran jasmani merupakan fondasi utama atlit pencak silat sebelum melangkah ketahap teknik, taktik dan mental. Dengan hal tersebut sangat dibutuhkan teknik dan metode latihan yang efisien untuk meningkatkan kesegaran jasmani atlit pencak silat, salah satunya dengan latihan circuit training. Latihan circuit training merupakan satu bentuk latihan yang dilakukan dalam satu putaran, dan selama satu putaran itu terdapat beberapa pos, pada setiap pos itu peserta melakukan tugas. Seperti latihan bersinambungan, dalam latihan sirkuit dapat dilakukan variasi latihan.

Berdasarkan hasil analisis hasil uji $-\mathrm{t}$ tersebut diartikan bahwa latihan circuit training menjadi salah satu latihan yang cukup efektif untuk meningkatkan kesegaran jasmani. Hal tersebut dikarenakan dalam latihan circuit training mengandung bentuk latihan kekuatan, daya tahan, daya ledak, fleksibilitas, koordinasi, kelincahan, kecepatan, reaksi, dan keseimbangan. Unsurunsur dalam setiap pos circuit trainingantaralain :

Jumping Jack (Pos 1)

Jumping jack merupakan salah satu latihan tubuh yang terdiri dari kombinasi gerakan aerobik dan ketahanan otot paha, bokong, pinggul, dan juga bahu. Tentunya unsur-unsur tersebut dibutuhkan di dalam olahraga pencak silat khususnya kategori tanding yang memerlukan hampir seluruh anggota gerak tubuh.

Air plane circles (Pos 2)

Air plane circle adalah sebuah latihan yang bertujuan untuk menguatkan otot lengan .pelaksanaanya yaitu dengan memutar lengan dengan posisi tangan lurus. Dirotasikan kedepan dan kebelakang dengan bergantian.

\section{Sit-Up (Pos 3)}

Sit -up adalah sebuah latihan yang bertujuan untuk melatih kekuatan otot perut .Pelaksanaannya yaitu dengan posisi berbaring lalu tangan mengepal di belakangkepala, kemudian kaki ditekuk dan melakukan gerakan berbaring dan duduk berulang kali.

Crab walk alias merangkak ala 
kepiting. Gerakan ini mudah dilakukan oleh anak-anak. Anak duduk dengan kaki di depan dan tangan di belakang, lalu angkat pinggul dari lantai sehingga mereka berjalan seperti kepiting. Gerakan ini bertujuan untuk mengembangkan kekuatan pinggul,paha dan lengan

\section{Push up (Pos 5)}

Push up adalah suatu gerakan yang membentuk kekuatan otot bisep maupun trisep. Posisi awal tidur tengkurap dengan tangan di sisi kanan kiri badan. Kemudian badan didorong keatas dengan kekuatan tangan. Posisi kaki dan badan tetap lurus atau tegap. Setelah itu, badan diturunkan dengan tetap menjaga kondisi badan dan kaki tetap lurus. Badan turun tanpa menyentuh lantai atau tanah.

\section{Jump Rope (Pos 6)}

Rope Jump adalah suatu bentuk latihan yang dilakukan dengan cara melakukan 1 kali lompatan keatas dengan 2 tungkai. Latihan ini juga akan membentuk kemampuan unsur kecepatan dan kekuatan otot yang menjadi dasar terbentuknya daya ledak otot.Gerakan dalam latihan Rope Jump sangat bermanfaat untuk mengembangkan daya ledak otot tungkai. Melalui latihan Rope Jump, maka daya ledak otot tungkai berkembang lebih maksimal sehingga akan mendukung kegiatan olahraga yang
e-ISSN : 2747- 013X

membutuhkan daya ledak otot tungkai Dengan latihan circuit training yang terus menerus tersebut beban tubuh akan terbiasa untuk menerima latihan, sehingga kesegaran jasmani akan terlatih menjadi lebih baik. Yang terpenting dalam latihan adalah intensitas latihan yang terus menerus, ditunjang dengan frekuensi latihan yang terus menerus secara otomatis akan meningkatkan intensitas latihan, yang mana dengan intensitas latihan banyak akan memberikan hasil yang semakin baik.

\section{KESIMPULAN}

Berdasarkan hasil pembahasan penelitian ini maka diperoleh kesimpulan, yaitu : terdapat pengaruh yang signifikan dengan pemberian latihan Circuit Training dengan menigkatnya tingkat kesegaran jasmani pada atlet pencak silat usia dini (9-12 tahun) pada tes awal (pre-test) yaitu 16,0 menjadi 20,25 pada tes akhir (post-test) di Perguruan Tapak Suci Gelanggang SD Muhammadiyah 18 Medan Tahun 2020.

Saran

Saran yang dapat diberikan peneliti adalah :

1. Agar dapat memberikan variasi latihan yang lebih untuk merangsang respon latihan dalam hal meningkatkan performa pertandingan terkhususnya dalam hal kondisi fisik termasuk 
KesegaranJasmani.

2. Disarankan kepada pelatih agar dapat menerapkan program latihan yang bervariasi dalam meningkatkan Kesegaran Jasmani atlet yang berpedoman pada perkembangan dan usia atlet.

3. Kepada atlet dalam pelaksaaan bentuk latihan agar lebih serius dan sungguh-sungguh dalam melaksanakan program latihan.

4. Kepada pengurus perguruan Tapak Suci Gelanggang SD Muhammadiyah 18 Medan agar kiranya lebih memperhatikan kemajuan atlet dan pelatih untuk kepentingan bersama.

5. Kepada para teman-teman mahasiswa FIK UNIMED agar dapat mencoba melakukan penelitian dalam bidang olahraga terutama melalui variasi-variasi latihan untuk meningkatkan KesegaranJasmani.

6. Kepada para pembaca yang mungkin akan melakukan penelitian dengan menerapkan bentuk latihan peningkatan Kesegaran Jasmani agar kiranya dapat mencoba dengan materi bentuk latihan yang lainnya.

\section{DAFTAR PUSTAKA}

Habibi, Risdam.(2014). Perkembangan Pergruan Tapak Suci Di Medan (1970-2013). Medan : FIS UNIMED.

Kusmanto. (2011). "Pengaruh metode circuit training terhadap kebugaranjasmani siswa kelas II SMP N 1 Arjosari Kabupaten Pacitan".Skripsi: FIK UNY.

Rusli Lutan, dkk. (2000). "Dasar-dasar Kepelatihan”. Jakarta: DepartemenPendidikan dan Kebudayaan.

Munas IPSI ( 2007). "Usia atlet yang dipertandingkan pada cabang pencak silat yaitu usia dini ( 9-12 tahun), pra remaja (1214 tahun ), dan dewasa (17-35 tahun)".

Dikdik dan Griwijoyo ( 2012). Ilmu kesehatan remaja. Rosdakarya: BandungPB IPSI (2007). Buku peraturan IPSI: Hal 2-3.

Wahyudin, Uyu. (2011). “ Penilaian Perkembangan Anak Usia Dini”. Bandung.Suyadi (2013). "Strategi Pembelajaran Pendidikan Karakter". Bandung : Remaja Rosdakarya.

Kartono, Kartini (1995). “ Psikologi Perkembangan Anak". Bandung : CV Mandar

Prawoto, Musan. (2007). “ kesegaran jasmani adalah kemampuan seseorang untuk menuaikan tugas sehari-hari dengan gampang tanpa lelah yang berlebihan,". Skripsi.

Wahjoedi, (2000 : 58). "Kesegaran Jasmani adalah kemampuan tubuh untuk melakukan tugas dan kegiatan sehari-hari dengan giat,". Skripsi. 
Ambarakumi (2007 : 1). "Menyebutkan bahwa beberapa ahli mengemukakan pendapatnya tentang pengertian, ,. Skripsi.

Hare ( 1982) . "Secara Teratur Dan Terencana Sehingga Mempertinggi Kemampuan Dan Kesiapan Olahragawan, "Skripsi.

Thomson ( 1993 : 61). "Latihan adalah proses yang sistematis untuk meningkatkan kebugaran atlet sesuai cabang olahraga yang dipilih". Skripsi.

Rama, deby.(2019) Pengaruh Latihan Drill Menggunakan Variasi Huruf W Terhadap Kemampuan Passing Bawah Peserta Ekstrakulikuler Bola Voli Putri SMA Negeri 5 Binjai. Unimed.Medan

Roque, E, et al. (2016).Volley Coaching Manual, Los angeles: Foundation.

Sari, I. E. P. (2020). Efforts to Improve Learning Outcomes passing Down Volleyball Variations Through Learning and Modified Ball On Private Junior High School eighth grade students Perbaungan Satria Dharma School Year 2019/2020: Efforts to Improve Learning Outcomes passing Down Volleyball Variations Through Learning and Modified Ball On Private Junior High School eighth grade students Perbaungan Satria Dharma School Year 2019/2020. Journal of Midwifery and Nursing, 2(1), 173-176.

Sudjana.( 2005 ). Metode Statistika.Bandung :Tarsito

Syafruddin.(2011). Ilmu kepelatihan olahraga. Padang: Tim Editor UNP Press Padang. 